\title{
System dynamics modeling of public health services provided by China CDC to control infectious and endemic diseases in China
}

This article was published in the following Dove Medical Press journal:

Infection and Drug Resistance

\author{
Meina $\mathrm{Li}^{1}, *$ \\ Wenya $\mathrm{Yu}^{1, *}$ \\ Wei $\operatorname{Tian}^{2, *}$ \\ Yang $\mathrm{Ge}^{3}$ \\ Yuan Liu' \\ Tao Ding ${ }^{\prime}$ \\ Lulu Zhang' \\ 'Department of Military Health \\ Service Management, College of \\ Military Health Service Management, \\ Second Military Medical University, \\ Shanghai, China; ${ }^{2}$ Medical Care \\ Department, Dalian Rehabilitation \\ Center of PLA, Dalian, China; ${ }^{3}$ School \\ of Public Health, Shanghai Jiao Tong \\ University School of Medicine, \\ Shanghai, China \\ *These authors contributed equally \\ to this work
}

Correspondence: Lulu Zhang

Department of Military Health Service Management, College of Military Health Service Management, Second Military Medical University, 800 Xiangyin Road, Shanghai 200433, China

Tel +86 02। 8I 87 |42।

Fax +86 02। 8I87 I436

Email zllrmit@aliyun.com
Background: Infectious and endemic diseases are a serious public health concern worldwide, and their prevention and treatment are globally controversial. This study aimed to establish an system dynamics (SD) model to analyze the factors influencing public health services provided by the Chinese Centers for Disease Control and Prevention (China CDC) to implement infectious and endemic disease control in China, by establishing more effective interventions to provide public health services and thus achieving the goal of controlling infectious and endemic diseases. Materials and methods: An SD model was constructed using the Vensim DSS program. Intervention experiments were performed using the SD model, which reflected the influences on disease control by adjusting the governmental investment and compensation level for public health products.

Results: The experimental results showed that increasing the governmental investment in China $\mathrm{CDC}$ and compensation level for public health products will significantly increase the public health product rate provided by China CDC.

Discussion: Problems with infectious and endemic disease prevention and treatment are the result of the system's incomplete functioning and limited health resources. To address the current problems and improve the system, the government should increase its investment in the public health service system and improve the compensation system to ensure smooth implementation of infectious and endemic disease prevention and treatment and, ultimately, improve public health in China. Keywords: epidemic model, transmission, spread, epidemiology, public health, system dynamics, disease management

\section{Introduction}

\section{Problem/significance}

The prevention and treatment of infectious and endemic diseases should be carefully considered, because they are both global issues. Infectious diseases occur mainly in developing countries, but owing to its mode of transmission, developed countries are always involved during epidemics. In 2017, 90 countries and areas had ongoing malaria transmission, ${ }^{1}$ an estimated 36.9 million people living with HIV at the end of 2017 and 940,000 died from HIV-related causes globally in 2017. ${ }^{2}$ Among the people who died from infectious diseases, $>90 \%$ had AIDS, infectious diarrhea, tuberculosis, malaria, or respiratory diseases. According to the World Health Statistics, infectious diseases, such as malaria, tuberculosis, AIDS, dengue, and measles, are long-time health risks, and solutions to these diseases should be found immediately. Half of the world's population has been reported to being predisposed to malaria, and among the 
estimated 219 million cases, malaria caused 435,000 deaths in $2017 .{ }^{1}$ The number of people living with HIV represents a worse tendency, particularly in sub-Saharan Africa. Neglected tropical diseases pose a severe threat to the poorest and most marginalized communities and cause millions of deaths; in particular, the incidence of dengue has dramatically increased in the recent decades. Therefore, WHO is calling for more efforts to prevent, treat, and eliminate infectious diseases. ${ }^{3}$ WHO has set some targets to achieve health-related Millennium Development Goals, including some regarding infectious diseases such as eliminating malaria in at least ten countries by $2020 .{ }^{4}$ In addition, WHO has analyzed the risk factors associated with diseases, such as their transmission; all these risk factors increase the probability of epidemics, such as diarrheal diseases (including cholera), hepatitis, and pneumonia. Encouraged by the WHO and the importance of preventing and treating infectious diseases for global health, scholars from different countries and regions have conducted related studies. Researches mainly concentrated on the prevention and treatment, assessment methods and models, and epidemiology. ${ }^{5}$ HIV/AIDS is the most controversial research topic, including its prevention and treatment, ${ }^{6-10}$ epidemiology and pathogenesis, ${ }^{11}$ and interventions. ${ }^{10,12-17}$ Other epidemics also caused much attention, such as dengue epidemics, ${ }^{18}$ hepatitis C, ${ }^{19,20}$ and influenza. ${ }^{21}$ Some studies focused on the epidemic prevention methods, ${ }^{22}$ the new epidemiological paradigm, ${ }^{23}$ and the optimal control of epidemic outbreaks. ${ }^{24}$ The EU also made great efforts to prevent epidemics. The ECDC has identified the major threats of epidemics and predicted the main risk factors faced by EU member countries and the European region in 2013. The ECDC analyzed seven types of infectious diseases, published an assessment report on the risks of infectious diseases in Europe, and included health risks in and outside of the EU, regarding the eight infectious diseases.

In the field of epidemiology, there is a special type known as endemic disease, which refers to the constant presence and/or usual prevalence of a disease or infectious agent in a population within a geographic area. ${ }^{25}$ Endemic disease often overlaps infectious disease. An infectious disease will disappear or transit into an endemic disease based on its pathogenicity and transmission mode. ${ }^{26}$ Some infectious diseases are endemic diseases in certain regions, for example, chickenpox is an endemic disease in the UK, malarial disease is endemic in Africa, and AIDS is becoming more and more endemic in Africa. Similar with infectious diseases, endemic diseases also threaten the health of the worldwide population in a particular way. If someone visits these endemic regions, especially the foreign workers, they will be exposed to these endemic diseases. Because of the constant existence of endemic diseases for many years, they even impose a far higher public health burden than infectious diseases ${ }^{27}$ and result in the loss of capacity for physical labor and threat to human health. ${ }^{28}$ Therefore, various countries and regions should pay special attention to different endemic diseases, owing to the regional characteristic; however, it must be recognized that endemic diseases can also cause threats globally due to the transmission between infectious diseases.

China is no exception to the burdens of infectious and endemic diseases. On the one hand, according to the law of the China on the Prevention and Treatment of Infectious Diseases, infectious diseases are divided into three categories: category A, including plague and cholera; category B, including 26 infectious diseases (viral hepatitis, AIDS, malaria, dengue fever, etc); and category $\mathrm{C}$, including 11 infectious diseases (influenza, epidemic parotitis, etc). Among the mortality rates of major diseases in urban areas in 2000, 2005, 2010, 2015, and 2016, infectious diseases (excluding respiratory tuberculosis) ranked $11 \mathrm{th}, 13 \mathrm{th}, 11 \mathrm{th}, 9 \mathrm{th}$, and 10th, respectively, with the component ratios of $0.67 \%, 0.66 \%$, $0.72 \%, 1.09 \%$, and $1.05 \%{ }^{29}$ The occurrence of infectious diseases showed a fluctuated trend in China but was always a serious threat to people's health. The Chinese Health Statistics 2017 reports that the top ten infectious diseases for morbidity in categories A and B are viral hepatitis, tuberculosis, syphilis, bacillary and amebic dysentery, gonorrhea, scarlet fever, AIDS, brucellosis, measles, typhoid, and paratyphoid. ${ }^{29}$ On the other hand, China is a country with serious endemic diseases. Endemic patients in China are seriously affected, widely distributed, and threatened. ${ }^{30}$ According to the National Health Commission of China, the most important endemic diseases in China are Kashin-Beck disease, Keshan disease, iodine deficiency disorders, endemic fluorosis, and arsenic poisoning. ${ }^{31}$ The "13th Five-Year" National Endemic Disease Prevention and Control Plan proposed that by 2020, China will continue to eliminate the harm of iodine deficiency disorders and maintain the basic elimination of endemic fluorine and arsenic poisoning, Kashin-Beck disease, and Keshan disease..$^{32}$ In this study, we focused on both infectious and endemic diseases. Based on the 28 infectious diseases in The Chinese Health Statistics 2015 and 2017, this study included 23 prevalent infectious diseases and excluded 5 temporarily eliminated infectious diseases. The included infectious diseases are epidemic encephalitis, typhoid and paratyphoid, brucellosis, infant tetanus, syphilis, epidemic cerebrospinal meningitis, epidemic hemorrhagic disease, 
gonorrhea, anthrax, rabies, scarlet fever, malaria, viral hepatitis, dengue, whooping cough, bacillary and amebic dysentery, tuberculosis, AIDS, leptospirosis, cholera, measles, plague, schistosomiasis, and H7N9 avian flu. In the field of endemic diseases, we focused on the five most significant diseases mentioned above, namely, Kashin-Beck disease, Keshan disease, iodine deficiency disorders, endemic fluorosis, and arsenic poisoning.

Therefore, considering the severity, harm, and burden of infectious and endemic diseases globally and in China, China, as an important country, should make great efforts to practice the prevention, control, treatment, and care of infectious and endemic diseases, which would provide valuable suggestions to other countries and regions.

Prevention and treatment of infectious and endemic diseases in China is dynamic and complex. Therefore, an SD is suitable to analyze these issues. SD is a computer-aided technique for policy analysis and simulation modeling, exploring dynamic issues arising in complex systems and assessing interventions. It is based on feedback system theory and refers to empirical testing and quantification.

SD combines social and behavioral science and helps achieve a deeper understanding of socioeconomic problems in large complex systems over time. As SD has developed, the extent of its application has expanded to economic fields, public health, policy analysis, ecosystems, environment issues, education, and epidemiology. Particularly, in the field of epidemiology, applications remain limited and are only found in tobacco and tuberculosis, ${ }^{33,34}$ Kawasaki disease epidemiology, ${ }^{35}$ obesity prevention and treatment, ${ }^{36-38}$ interventions in opioid use and abuse, ${ }^{39} \mathrm{HIV}$ prevention and treatment, ${ }^{40,41}$ and chlamydia infection analysis. ${ }^{42}$ Therefore, this study selected SD as an analyzing tool.

\section{Objective}

This study aimed to establish an SD model to analyze the factors influencing public health services provided by China CDC to meet the need of infectious and endemic disease prevention and control, helping us make more scientific and practical interventions for public health services, and thus achieving the goal of controlling infectious and endemic diseases.

\section{Material and methods SD model}

SD contains four components (stock variables, flow variables, converters, and connectors) and is mainly constructed using causal loop and stock and flow diagrams. The stock and flow variables are essential components of SD structures, constituting the stock and flow diagrams with information. The stocks are state variables; the flows represent rates of change. SD models also include some cause-and-effect chains, and these closed chains are called feedback loops, which can be divided into reinforcing and balancing feedback loops and help understand the interrelations and interactions between elements of the system. In SD models, the causal loop diagrams consist of some feedback loops, and the stock and flow diagrams are based on the causal loop diagrams; by combining the two diagrams, the relationships among variables with the potential to change over time are understood.

An SD simulation often includes the following six steps. First, identify problems in the system and define the boundary dynamically. Second, based on the system's dynamic changes and hypothesis, establish the causal loop and stock-flow diagrams. Third, identify and change the most significant stocks and flows. Fourth, determine the functions, equations, and initial values of some variables. Fifth, analyze and test the correspondence between the model and reality. Finally, present a discussion and conclusion according to the simulated results. The SD simulation can be completed using the Vensim DSS computer software, which allows us to conceptualize, document, simulate, analyze, and optimize models of dynamic systems. Thus, the Vensim DSS was employed in this study to help create the SD model.

\section{Model description}

A disease control system is designed to prevent and control epidemics and other diseases and aims to decrease morbidity, improve the environment, and enhance the population's health condition. The center of the disease control system is China CDC where the socioeconomic, national policy, financial, human resource, epidemics, and living environment systems are communicated, connected, and interacted to determine the functions of the disease control system. Thus, the aim of enhancing the population's health state can be achieved, and the whole population as well as China $\mathrm{CDC}$ will benefit from the system. A disease control system involves three major parts: the government, consumer, and supplier. Governments will influence the disease control systems by adjusting price and compensation systems and changing the investment in China CDC. All these factors as the demand for an EPI and conditions of contagious and endemic diseases influence the demand for disease control services and products. The supplier is mainly influenced by the input, including manpower resource allocation and the funding system and its allocation. 
The three parts interact with each another, determining and sustaining the disease control system.

\section{Causal loop diagram}

Various studies demonstrated that enlarging the scale of vaccination, increasing the vaccination rate, ${ }^{43}$ and controlling the sources of infection ${ }^{44}$ are some effective methods for controlling infectious diseases. In addition, the government budget, the compensation level for public health products, the population's health conditions, and the external and internal environment of the system are concluded to play a significant role in the disease control system. Figure 1 shows the causal loop diagram, which describes the cause-and-effect relation and interactions of factors affecting the disease control system. The loops in the diagram are described as follows.

The China CDC's investment and compensation system and the income mechanism were analyzed. Its incomes are mainly from government financial investment and paid service income. The governmental financial investment in the health delivery system accounted for a relatively small proportion (30.41\%) of the total health expenditure in $2011,{ }^{45}$ and the investment in China CDC was much smaller. This caused China CDC to depend more on service incomes, dramatically impeding the disease control process and the achievement of health condition enhancement. The China CDC's paid service incomes can be divided into two parts, private and quasi-public product incomes, directly cutting down the provision of public health products that cannot provide financial benefits for China CDC. However, the price of the three types of products and the amount of products provided by China CDC are influenced by the compensation level of the public health product: as the compensation level of a public health product increases, so does the amount of products provided by China CDC. Thus, the function of the disease control system would be realized more completely. The China CDC has been known to play a significant role in satisfying the demand for disease control, mainly among the population with contagious and endemic diseases and the population requiring EPI.

The flow directions of resources and their allocation were analyzed. In this diagram, the medical resources referred to are China CDC capital and manpower. In 2014, the government investment in China CDC was 31,047,600,000 CNY, accounting for only $0.29 \%$ of the government health expenditure. ${ }^{45}$ Combined with the low compensation level of public health products, the total capital of China CDC was completely insufficient. Hence, China CDC's output capability was very poor, the China CDC's provision of public health products was insufficient, China CDC was more willing to provide private and quasi-public products to make more earnings, and the price of three types of health products would be higher because of the poor compensation system. Meanwhile, owing to the more volatile manpower of China CDC, its output capability was greatly influenced and weakened, seriously hindering the process of disease control. The model of "grasp the shadow instead of the essence" could be used in analyzing the interaction between paid and public services provided by China CDC. Under the circumstances

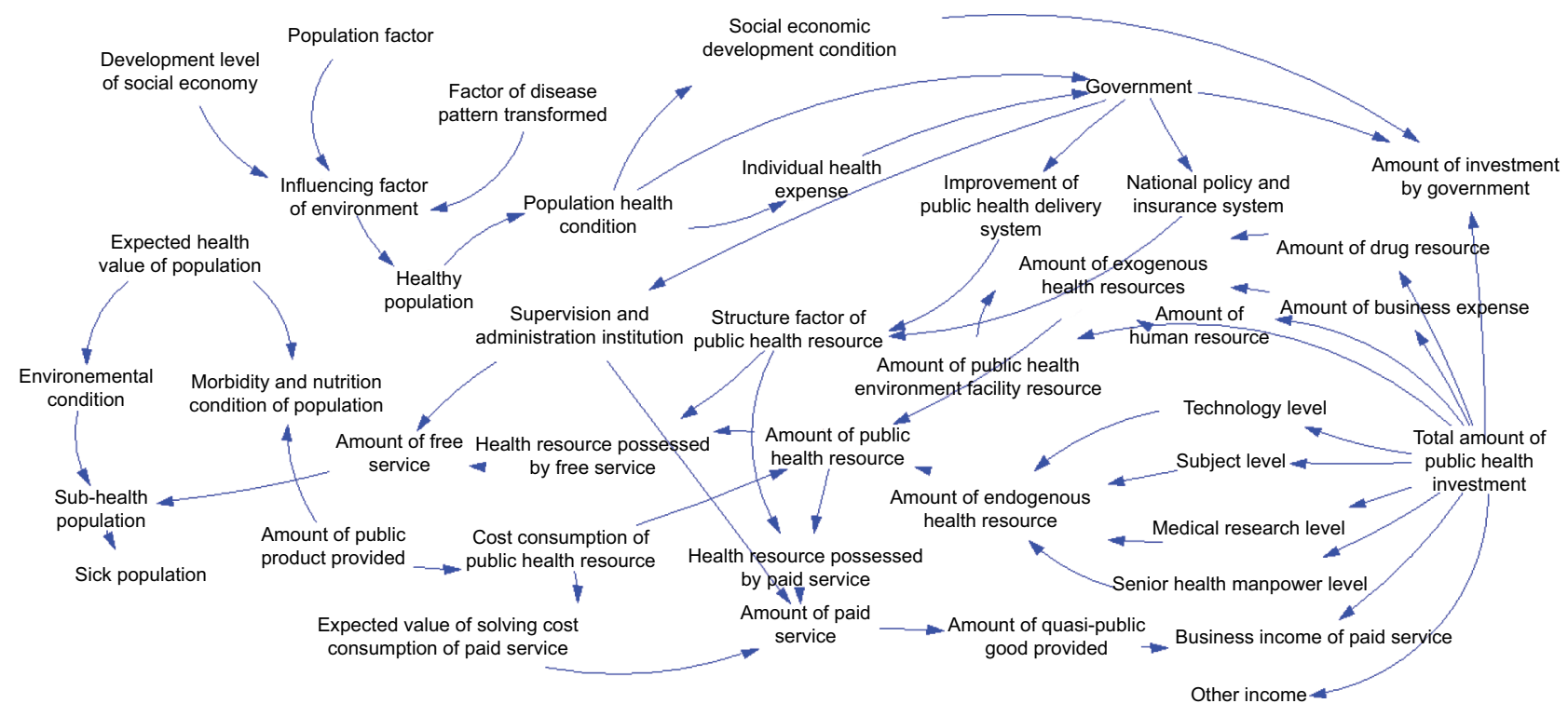

Figure I Cause-and-effect relation chart of factors affecting the disease control system. 
that China CDC's total public health resources were insufficient, China CDC would try to overcome the embarrassing situation by decreasing the provision of public services and increasing the paid services, thus weakening the functions of China CDC and impeding the enhancement of the people's health states. Therefore, the optimum solution to the deficient disease control system should be identified.

\section{Stock-flow diagram Model description}

To further quantify the disease control system, its three parts were established: the infectious disease, the endemic disease, and China CDC subsystems. The former two subsystems greatly influence the China CDC subsystem, mainly affecting the demand, and the latter, in turn, affects the tendency and stability of the former two subsystems. Various input and output variables in the three subsystems form the interrelationships in the disease control system, providing the possibility of constructing an SD model to study the disease control system. Data were extracted from the Chinese Health Statistical Yearbook 2015. ${ }^{45}$

Figure 2 shows the SD model of the disease control system. This diagram would help policymakers, health managers, and common readers understand the structure and interaction of the system, thus making more scientific decisions and policies to support the disease control program. The diagram includes some different symbols: rectangles indicate stock variables, rate variables are linked by doublelined arrows, and causal relationships among variables are shown by single-lined arrows. In this stock-flow diagram, stock variables are the total population, China CDC capital, and China CDC manpower. Flow variables are increment of population, decrement of population, increment of China CDC capital, decrement of China CDC capital, increment of China CDC manpower, and decrement of China CDC manpower. Auxiliary variables include rates of public health products provided by China CDC, output capability of China $\mathrm{CDC}$, and amount of public health products provided by China CDC. Initial variables include birth rate, mortality rate, initial value of government investment in China CDC, and morbidity and fatality rates of 23 notifiable diseases. Intervention variables are government investment in China CDC and compensation level of public health product. The observation variable is the rate of public health products provided by China CDC.

\section{Calculation of variables}

First, the initial values of variables in the disease control model were determined based on several methods, such as the national statistics, ${ }^{45} \mathrm{SD}$, econometrics, statistics, Delphi method, and on-site survey. For instance, the total number of people was $1,367,820,000$ in 2014 , and the birth and mortality rates were $12.37 \%$ and $7.16 \%$; therefore, the birth and mortality rates every month were set to $0.01237 / 12$ and $0.00716 / 12$, respectively.

Second, values of the stock variables were calculated based on the initial value of the stock variables and the flow variables (increment and decrement values). For example, the

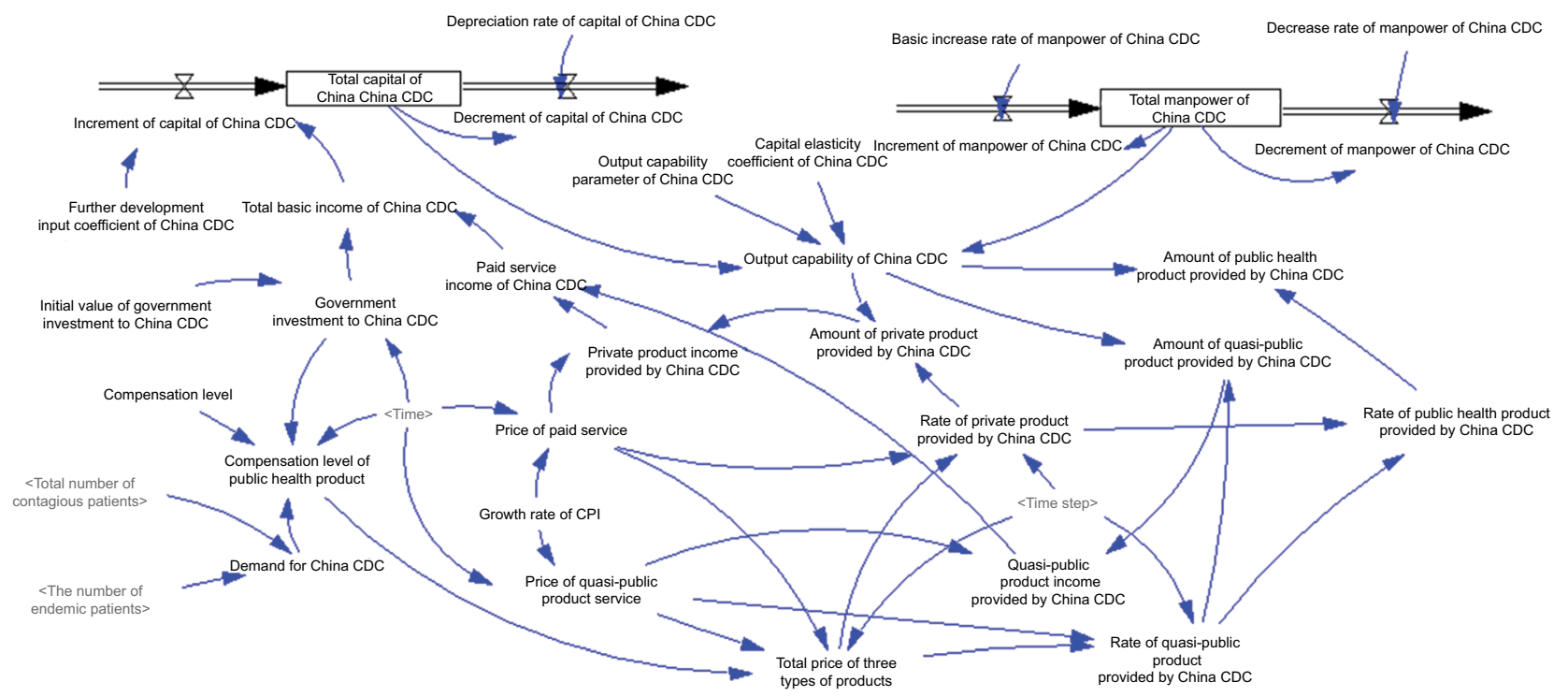

Figure 2 Capital of China CDC, manpower of China CDC, and service provided by China CDC.

Notes: Different shading of text tone in figure indicates model consists of several logically dedicated parts ie, subdiagrams. Each subdiagram containing a number of tightly interrelated variables. Lighter shading of text tone indicates variables used in several subdiagrams.

Abbreviation: China CDC, Chinese Centers for Disease Control and Prevention. 
initial total capital value of China CDC was 39,299,210,000 CNY, and the initial total manpower value of China CDC was 192,397. Therefore, the formulation of the total capital and manpower of China CDC was constructed as follows: total capital of China CDC $=39,299,210,000+$ increment of capital of China CDC - decrement of capital of China CDC and total manpower of China $\mathrm{CDC}=192,397+$ increment of manpower of China CDC - decrement of manpower of China CDC.

Third, some auxiliary variables determined the flow variables and linked the stock and flow variables. The increment of China CDC capital was determined based on the total basic income and further development input coefficient of China CDC, and the decrement of capital of China CDC was influenced by the total and depreciation rates of China CDC capital. The increment of China CDC manpower was reflected by the total and basic increasing rate of China CDC manpower, and the decrement of China CDC manpower was reckoned by the total and decreasing rate of China CDC manpower.

Fourth, the main observational variables were the amount of health products provided by China CDC, which was influenced by its output capability and rates of health products provided. The output capability of China CDC was formulated by the total capital and total manpower of China CDC. Thus, the formulations of the three types of health products could be constructed as follows: amount of public products provided by China $\mathrm{CDC}=$ China $\mathrm{CDC}$ output capability $\times$ rate of public product provided by China $\mathrm{CDC}$; amount of private product provided by China $\mathrm{CDC}=$ China $\mathrm{CDC}$ output capability $\times$ rate of private product provided by China $\mathrm{CDC}$; and amount of quasi-public product provided by China CDC $=$ China $\mathrm{CDC}$ output capability $\times$ rate of quasi-public product provided by China CDC.

Fifth, the number of endemic patients was the total number of five different endemic patients, which came from the population of five disease counties and their morbidity (Figure 3). Morbidity of these diseases was extracted from the Chinese Health Statistical Yearbook 2015. The population of five disease counties was calculated according to the formulation of stock variables. Take the population of endemic fluorosis county as an example. The initial population of endemic fluorosis county was 94,537,000, and the increment and decrement of endemic fluorosis population were determined according to the population of endemic fluorosis county, birth rate, and death rate. Therefore, the five formulations were constructed as follows: Population of endemic fluorosis county $=94,537,000+$ increment of endemic fluorosis population - decrement of endemic fluorosis population; popula- tion of Keshan disease county $=61,892,000+$ increment of Keshan disease population - decrement of Keshan disease population; population of Kashin-Beck disease county = $37,715,000+$ increment of Kashin-Beck disease population - decrement of Keshan disease population; population of iodine deficiency disorder county $=1,319,645,000+$ increment of iodine deficiency disorders population - decrement of iodine deficiency disorders population; and population of endemic arsenic poisoning county $=1,349,000+$ increment of endemic arsenic poisoning population - decrement of endemic arsenic poisoning population.

Finally, the total number of contagious patients was the sum of patients suffering from 23 notifiable contagious diseases (Figure 4). The numbers of various patients were all reckoned based on the stock variable discipline. For example, the number of patients with viral hepatitis was formulated as the initial number of patients with viral hepatitis $(1,223,021)$ + its increment - its decrement. In addition, the increment of patients with viral hepatitis was calculated as the total population $\times$ morbidity of virus hepatitis, where the total population was $1,367,820,000+$ increment - decrement of population, and the morbidity from viral hepatitis was obtained from the Chinese health statistical yearbook. Similarly, decrement of patients with viral hepatitis was determined as the number of patients with viral hepatitis $\times$ its fatality rate. Therefore, other contagious diseases were calculated the same as viral hepatitis.

All variables and equations are listed in Supplementary material.

\section{Model validation}

To validate the model, the initial value of variables was set in 2014, which was simulated in the next 3 years (2014-2016). This would help us demonstrate whether the model aligns with the historical evolution of China's health delivery system. The validation results are shown in Table 1 . The actual data were taken from historical records of the Chinese Health Statistical Yearbook 2017, ${ }^{29}$ and the simulated data were the results of validation analysis. One can see that deviation between the actual and simulated data was not significant - namely, between $-0.8162 \%$ and $0.1550 \%$, which is a reasonable range. Thus, the model is considered validated and reasonable.

\section{Sensitivity analysis}

To test the validity and reliability of this model, sensitivity analysis was conducted by changing some parameter values in a restricted and reasonable range. If the output variable fluctuates in a gentle range but remains the overall trend, the 


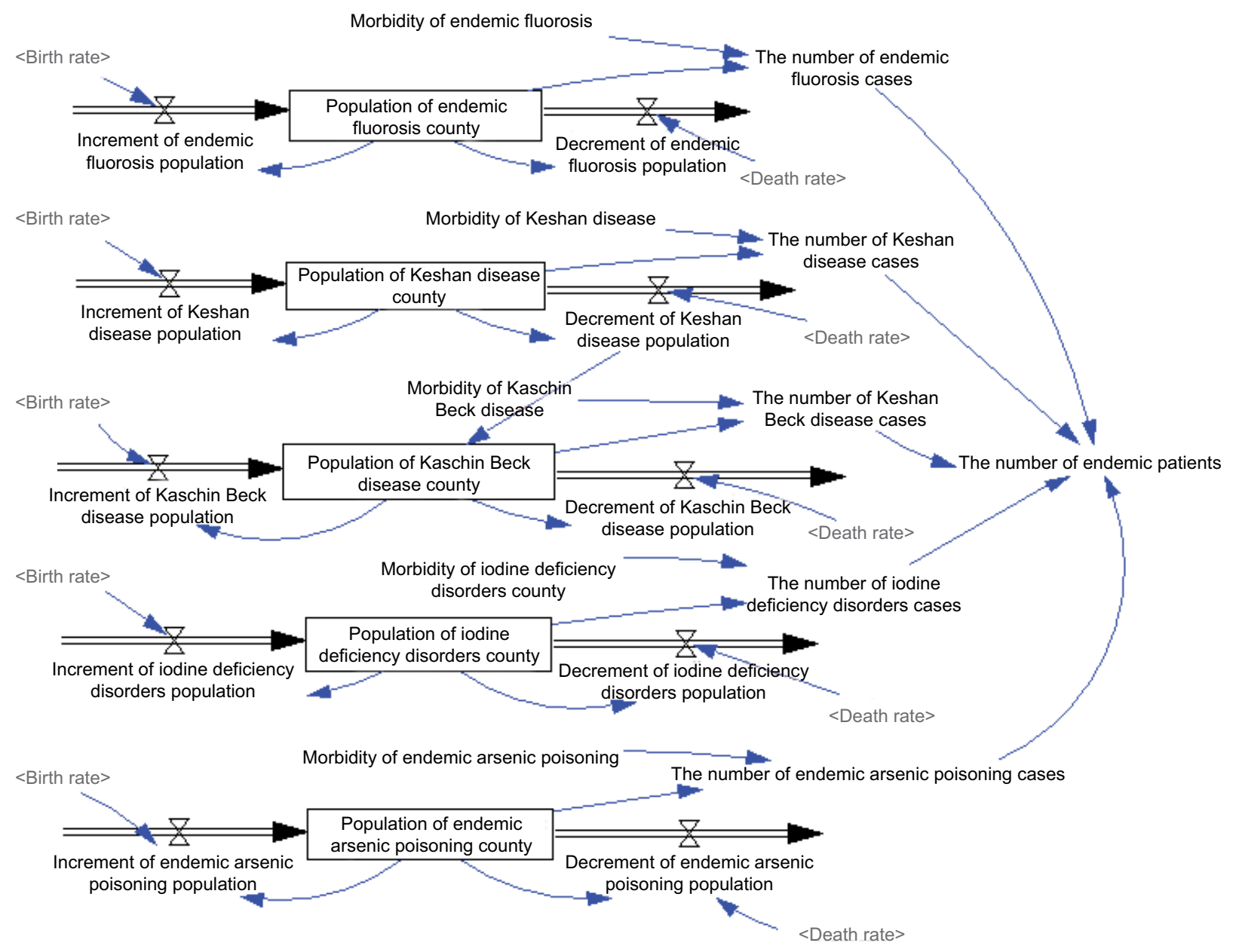

Figure 3 Number of endemic patients in the disease control system.

Notes: Different shading of text tone in figure indicates model consists of several logically dedicated parts ie, subdiagrams. Each subdiagram containing a number of tightly interrelated variables. Lighter shading of text tone indicates variables used in several subdiagrams.

model can be considered valid and reliable. ${ }^{46}$ Sensitivity (S) is calculated according to $\Delta \mathrm{Y}(t) / \mathrm{Y}(\mathrm{t})$ and $\Delta \mathrm{X}(t) / \mathrm{X}(t)$, which represent the changes in output variables and changing parameter, respectively. Therefore, the formulation of sensitivity is $\mathrm{S}(t)=\frac{\Delta \mathrm{Y}(t) / \mathrm{Y}(t)}{\Delta \mathrm{X}(t) / \mathrm{X}(t)}$.

Two parameters were selected for the sensitivity analysis, with the variation rates between $-20 \%$ and $20 \%$ of the current values. The two variables were the compensation level and initial government investment to China CDC. The output variable was the rate of public health products provided by China CDC. The model operated 200 times, and this procedure was conducted by Vensim. Figure 5 shows that among the 200 cases, $50 \%$ of the output variables were in the yellow, $75 \%$ in the green, $95 \%$ in the blue, and $100 \%$ in the gray area. This result suggested that the output variable did not show an extreme variation but changed in a slight and reasonable range. Therefore, the model is stable, reliable, and suitable for simulation analysis.

\section{Results}

In this study, the SD model simulated the policy intervention experiments, which reflected the influences on disease control by changing different system parameters.

\section{Adjusting the governmental investment in China CDC}

Figure 6 shows the influence of governmental investment in China CDC on the rate of public health products they provided. According to the Chinese Health Statistical Yearbook 2015, the budget received by the China CDC consists of financial subsidy income from the government, amounting to $31,047,600,000 \mathrm{CNY}$. Therefore, the initial governmental investment in China CDC in January 2014 was determined as $31,047,600,000 / 12 \mathrm{CNY}$. In test 1 , the initial value decreased to $10 \%$, in test 2 , it was set twice its current value, and in test 3 , it was set ten times its current value. China CDC provided services such as public health products (including infectious 


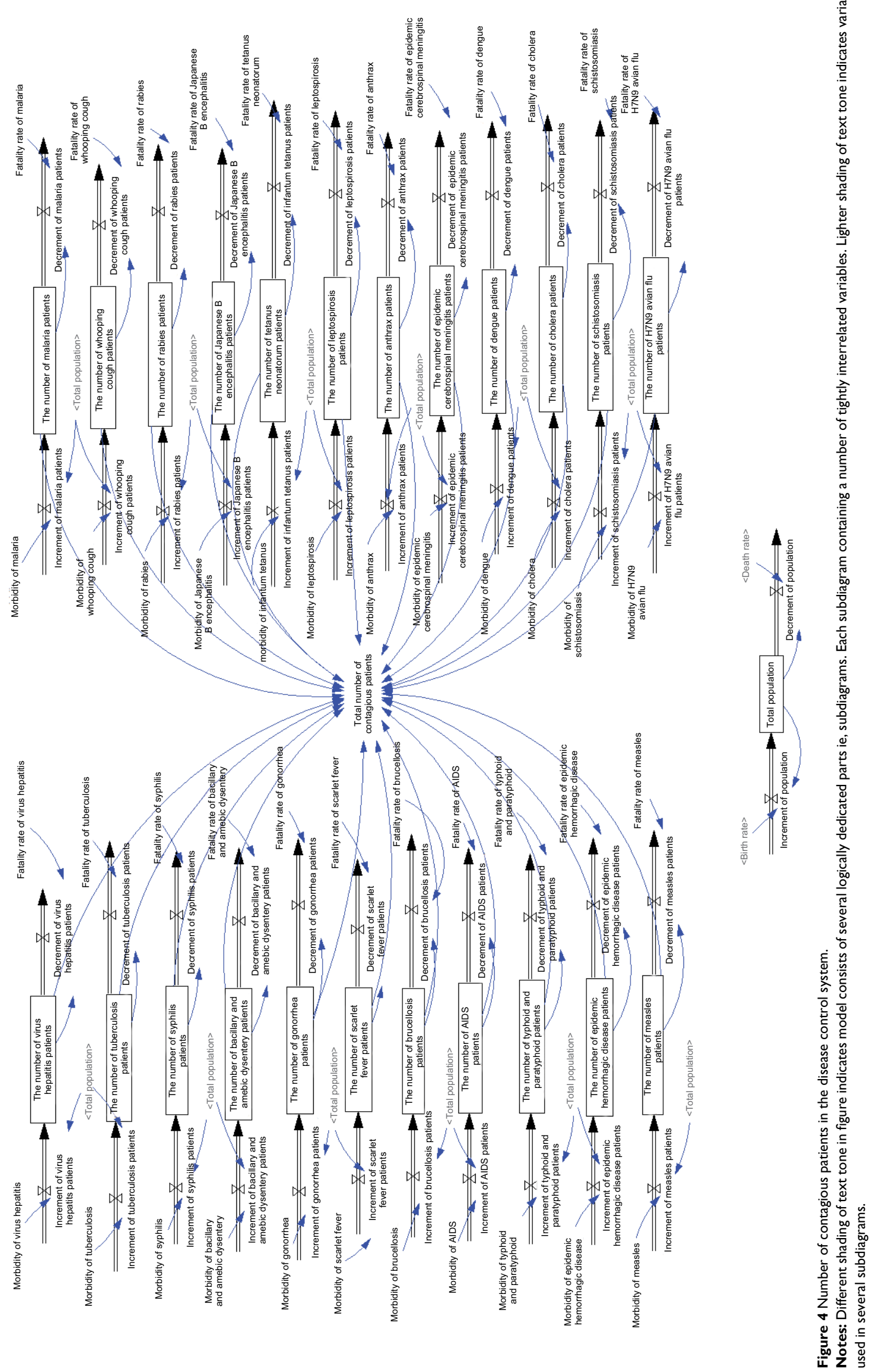


Table I Validation analysis of the model

\begin{tabular}{|l|l|l|l|l|}
\hline Year & & $\mathbf{2 0 1 4}$ & $\mathbf{2 0 1 5}$ & $\mathbf{2 0 1 6}$ \\
\hline Total & Actual data, $\mathrm{n}$ & 192,397 & 190,930 & 191,627 \\
manpower of & Simulated data, $\mathrm{n}$ & 192,397 & 191,226 & 190,063 \\
China CDC & Deviation & $0 \%$ & $+0.1550 \%$ & $-0.8162 \%$ \\
\hline
\end{tabular}

Abbreviation: China CDC, Chinese Centers for Disease Control and Prevention. and endemic diseases control), quasi-public products, and private products. Therefore, the rate of public health products provided by China CDC reflected the government's efforts to prevent and control infectious and endemic diseases. The results from these four different scenarios represented that

Sensitivity analysis

Current

$50 \% \quad 75 \% \quad 95 \% \quad 100 \%$

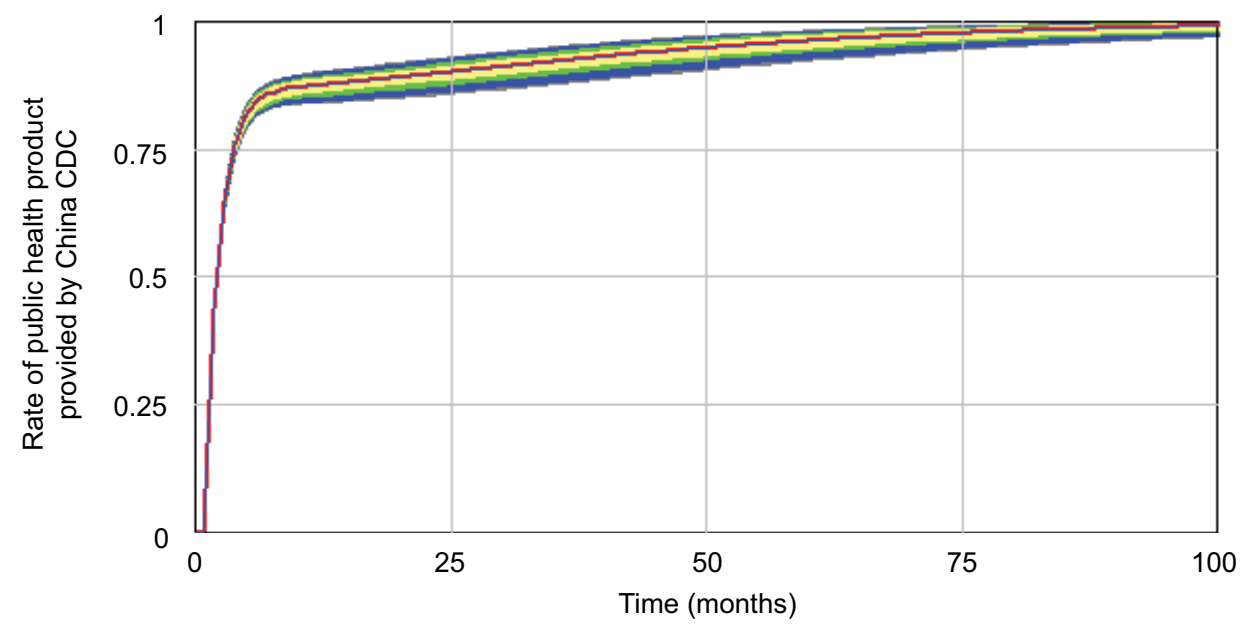

Figure 5 Sensitivity analysis of the model.

Abbreviation: China CDC, Chinese Centers for Disease Control and Prevention.

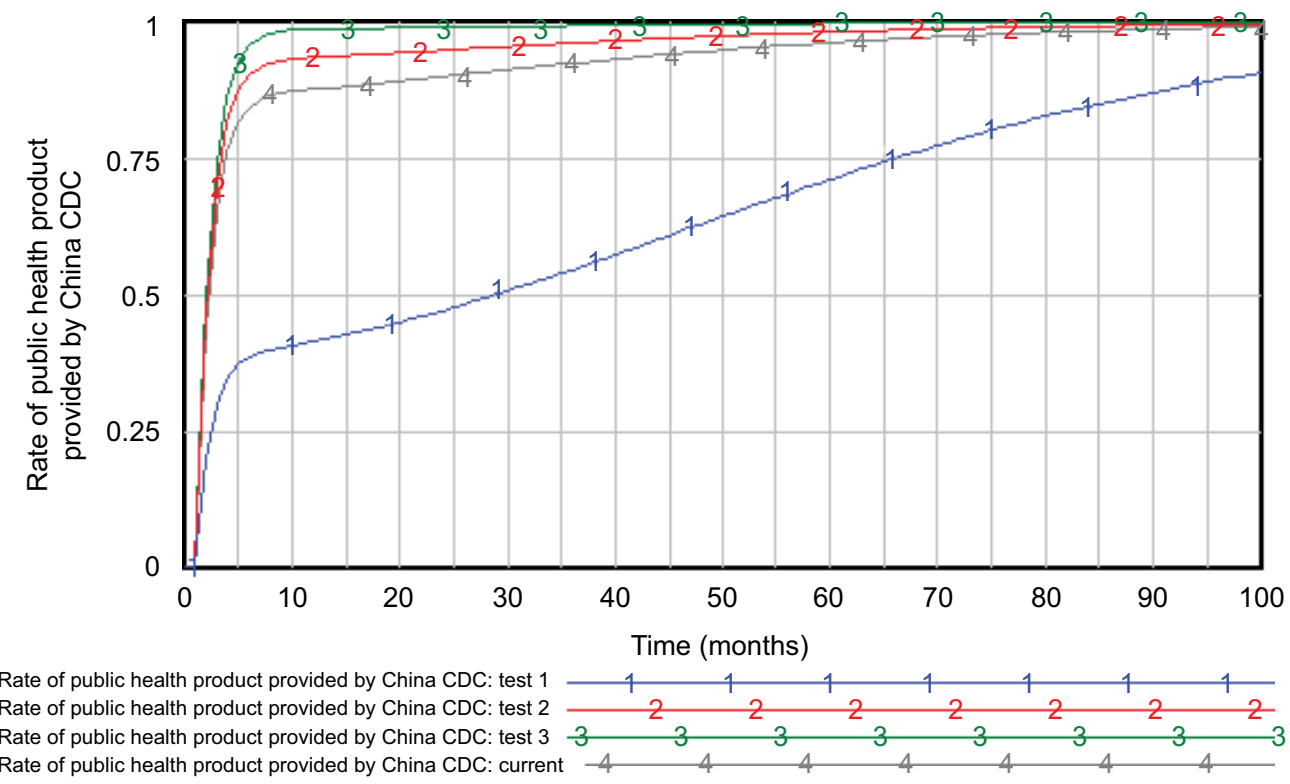

Figure 6 Effects of governmental budget in China CDC on the rate of public health products they provided.

Abbreviation: China CDC, Chinese Centers for Disease Control and Prevention. 
as the governmental budget in China CDC increases, the rate of public health products they provided also increases significantly, which may lead to the growth of output capability of China CDC.

\section{Adjusting the compensation level of public health products by the government}

Figure 7 shows the changes in the rate of public health products provided by the China CDC under various compensation levels for public health products by the government. From tests $1-3$, the compensation levels for public products by the government were changed to $20 \%(0.01)$, twice $(0.1)$, and ten times $(0.5)$ their current values $(0.05)$, respectively. The results showed that the higher compensation level for public products correlated with higher rates of public health products provided by the China $\mathrm{CDC}$, which improves the compensation level by increasing the rates they provided.

\section{Discussion}

Based on these results, combined with literatures, we present some suggestions for epidemic prevention and treatment, mainly concentrating on three aspects.

First is to enhance the support of infectious and endemic disease prevention and treatment. Regarding health care equality, to ensure basic public health services for the whole population, the support of infectious and endemic disease prevention and treatment should be enhanced. According to other countries' experience, the main influencing factor of making public health policies is the stakeholders, and among them, the role of government is of great importance. ${ }^{47}$ The government can determine specific polices, affect the implementation of public health services, and influence the effects and efficiencies of epidemic control. In addition, more attention must be paid to health staff. Increasing salaries and welfare of health staff will improve the implementation of free epidemic prevention and treatment. Currently, contradictions between the health staff and patients, poor working environments, and salaries prevented the provision of effective public health services. ${ }^{48}$ Regarding the reality of oversupply and induced demand of health care, the medical cost should be reduced. Increasing the total funds on the health department will change health care suppliers' behaviors and promote epidemic prevention and treatment. ${ }^{49}$

Second is to increase the governmental budget for public health services. Various studies have highlighted an evident relationship between the government's financial responsibility and public health services. In accordance with these results, the government should undertake the financial support for public health service, thus ensuring efficient implementation of health care services and decreasing the risk of disease transformation..$^{50}$ Other evidence suggests that increasing financial budgets for the public health system will

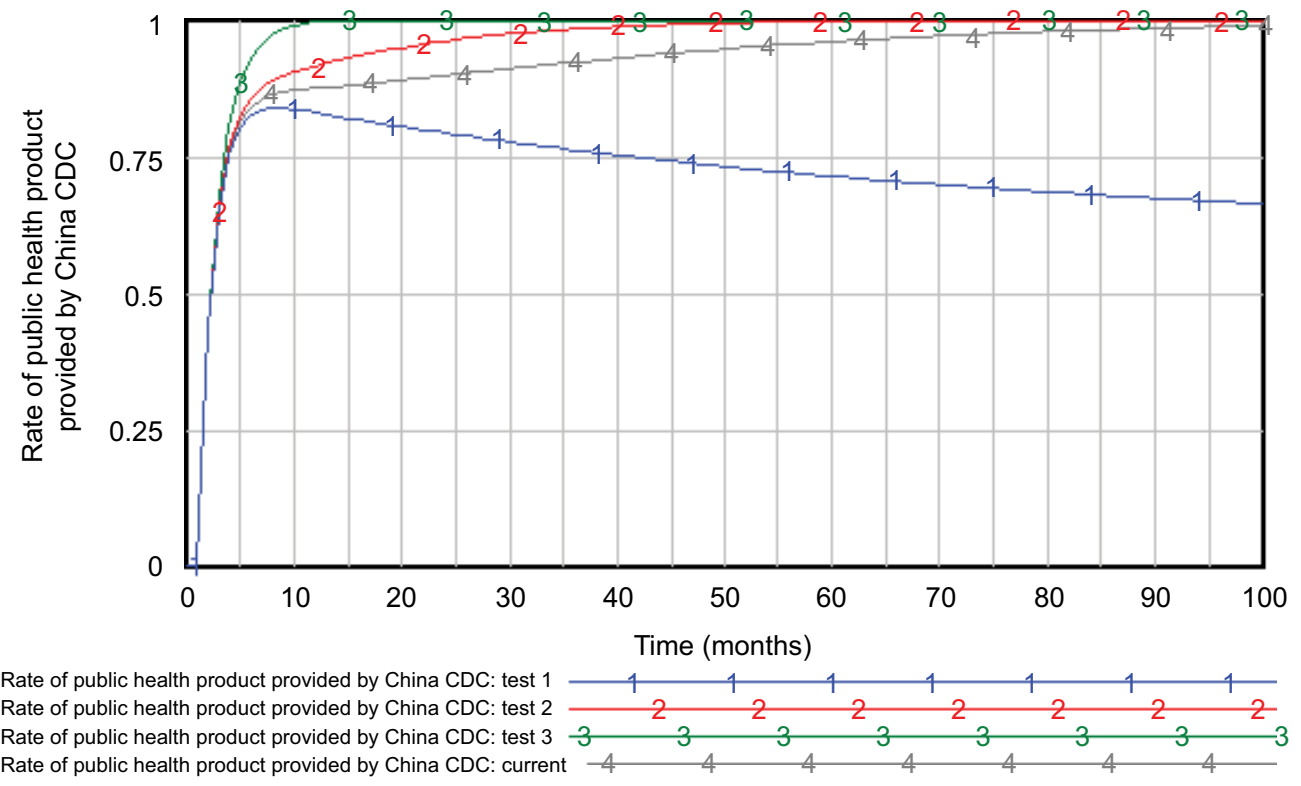

Figure 7 Effects of the compensation level for public products by the government on the rate of public health products they provided. Abbreviation: China CDC, Chinese Centers for Disease Control and Prevention. 
increase the possibility of accessing health treatment ${ }^{51}$ and that increasing the investment on health departments will improve the health services provided to the population in the community and promote the population's health condition. ${ }^{52}$ Therefore, the governmental investment plays a significant role in the process of advancing public health services and satisfying the demand for epidemic control in the whole population. Although it is a good solution, some limitations on the government funding situation should be recognized. This study test showed that even increasing the governmental investment in the China CDC to ten times its current value, the rate of public health products they provided continuously increased significantly. However, investing ten times more funding is a huge issue, especially in developing countries. Therefore, to be more realistic, comprehensive, and efficient, its management should not only rely on governmental investment but also on other agents, such as corporates, individuals, and social organizations. ${ }^{32}$ This was also supported by Medley and Vassall, who pointed out that with the transformation of infectious diseases into endemic diseases, the governments' responsibility started to move to individuals even though governments still provide some funding for treatment. ${ }^{27}$ As a result, it would be feasible to encourage more responsibilities from corporates, individuals, and social organizations when increasing the governmental investment.

Third is to improve the compensation system. At present, the compensation for disease prevention and treatment system and for public health service staff is extremely inadequate. Based on the reality, the loss of benefits owing to free public services should be compensated, thus gaining more support from health staff to implement epidemic control policy and to ensure the citizens' rights and interests to have access to public health services. ${ }^{53}$ In addition, governmental compensation for the China CDC will ensure their responsibilities to provide public health products and services. ${ }^{54}$ More compensation available for epidemic prevention and treatment will make the China CDC depend less on economic incomes and control the epidemics more efficiently. ${ }^{55}$ Consequently, improving the compensation system will help improve the responsibilities of the China CDC and deal with and control epidemics with high quality and efficiency.

Based on our literature review, this is the first study on China's epidemic control system using an SD model. Owing to the model's immaturity, some aspects remained to be improved, such as the application of more accurate data and stricter assumptions. Although the SD model has some deficits, it still allowed us to evaluate the public health system and estimate the epidemic control effects.
Some limitations should be dealt with in the future. This is the first time a study has constructed an SD model to examine an epidemic prevention and treatment system and to simulate the policy interventions; therefore, several assumptions were adjusted and simplified, some factors were neglected, and some connections were abstracted. In future studies, these deficiencies should be improved, so that the system can be enhanced to solve problems and promote efficient system operation more accurately.

This study has several limitations. As it is the first time that an SD model was used to study public health services provided by the China CDC in order to meet the needs of infectious and endemic disease control in China, relationships between subsystems have been simplified. Furthermore, several factors such as the cure rate were not considered in the model. Future studies will address these limitations and enhance the associations between the model and actual interventions.

\section{Conclusion}

The problem with infectious and endemic disease prevention and treatment system is the result of its incomplete functions and limited health resources. Under the current situation and systematic structure, because health institutions pursue economic benefits excessively, the whole system pays more attention to the treatment than the prevention of diseases, which in turn hinders epidemic control. To address the problems and improve the system, the government should increase its investment in the public health service system and improve the compensation system to ensure smooth implementation of epidemic prevention and treatment and, ultimately, improve the health status of the whole population in China.

\section{Abbreviations}

SD, system dynamics; China CDC, Chinese Centers for Disease Control and Prevention; EU, European Union; ECDC, European Center for Disease Prevention and Control; EPI, Expanded Program on Immunization.

\section{Acknowledgments}

Financial support for this study was provided entirely by National Natural Science Foundation of China (71673291, 71303248, 71233008, 91224005, 71774167), the Joint Research Project of Major Disease of Shanghai Health System (2013ZYJB0006) and the Major Project in the "12th Five-Year Plan" of the People's Liberation Army (AWS12J002), and Young Scientist Fund of Second Military Medical University (2012QN09). The funding agreement 
ensured the authors' independence in designing the study, interpreting the data, writing, and publishing the report.

\section{Disclosure}

The authors report no conflicts of interest in this work.

\section{References}

1. World Health Organization. Malaria; 2017. Available from: http://www. who.int/mediacentre/factsheets/fs094/en/. Accessed August 24, 2018.

2. World Health Organization. HIV/AIDS: key facts; 2018. Available from: https://www.who.int/news-room/fact-sheets/detail/hiv-aids. Accessed August 24, 2018.

3. World Health Organization. Ten years in public health 2007-2017; 2017. Available from: http://www.who.int/publications/10-year-review/ dg-letter/en/. Accessed August 24, 2018.

4. World Health Organization. Malaria control improves for vulnerable in Africa, but global progress off-track; 2016. Available from: https:/www. who.int/news-room/detail/13-12-2016-malaria-control-improves-forvulnerable-in-africa-but-global-progress-off-track. Accessed December $17,2018$.

5. Wen TH, Chin WC. Incorporation of spatial interactions in location networks to identify critical geo-referenced routes for assessing disease control measures on a large-scale campus. Int J Environ Res Public Health. 2015;12(4):4170-4184.

6. Vagenas P, Azbel L, Polonsky M, et al. A review of medical and substance use co-morbidities in central Asian prisons: implications for HIV prevention and treatment. Drug Alcohol Depend. 2013;132:S25-S31.

7. Stimson GV. AIDS and injecting drug use in the United Kingdom, 1987-1993: the policy response and the prevention of the epidemic. Soc Sci Med. 1995;41(5):699-716.

8. Degenhardt L, Mathers BM, Wirtz AL, et al. What has been achieved in HIV prevention, treatment and care for people who inject drugs, 2010-2012? A review of the six highest burden countries. Int J Drug Policy. 2014;25(1):53-60.

9. Tran BX, Ohinmaa A, Duong AT, et al. Cost-effectiveness of integrating methadone maintenance and antiretroviral treatment for HIV-positive drug users in Vietnam's injection-driven HIV epidemics. Drug Alcohol Depend. 2012;125(3):260-266.

10. Eaton JW, Menzies NA, Stover J, et al. Health benefits, costs, and costeffectiveness of earlier eligibility for adult antiretroviral therapy and expanded treatment coverage: a combined analysis of 12 mathematical models. Lancet Glob Health. 2014;2(1):e23-e34.

11. Maartens G, Celum C, Lewin SR. HIV infection: epidemiology, pathogenesis, treatment, and prevention. Lancet. 2014;384(9939):258-271.

12. Tran BX, Nguyen N, Ohinmaa A, et al. Prevalence and correlates of alcohol use disorders during antiretroviral treatment in injection-driven HIV epidemics in Vietnam. Drug Alcohol Depend. 2013;127(1-3):39-44.

13. Reid A, Scano F, Getahun H, et al. Towards universal access to HIV prevention, treatment, care, and support: the role of tuberculosis/HIV collaboration. Lancet Infect Dis. 2006;6(8):483-495.

14. El-Bassel N, Gilbert L, Terlikbayeva A, et al. Effects of a couple-based intervention to reduce risks for HIV, HCV, and STIs among druginvolved heterosexual couples in Kazakhstan: a randomized controlled trial. J Acquir Immune Defic Syndr. 2014;67(2):196-203.

15. Dawson Rose C, Gutin SA, Reyes M. Adapting positive prevention interventions for international settings: applying U.S. evidence to epidemics in developing countries. JAssoc Nurses AIDS Care. 2011;22(1):38-52.

16. Bach Xuan T, Ohinmaa a, Long Thanh N. Quality of life profile and psychometric properties of the EQ-5D-5L in HIV/AIDS patients. Health Qual Life Outcomes. 2012;10:132.

17. Hull MW, Montaner JS. HIV treatment as prevention: the key to an AIDS-free generation. J Food Drug Anal. 2013;21(4):S95-S101.

18. Larrieu S, Cassadou S, Rosine J, et al. Lessons raised by the major 2010 dengue epidemics in the French West Indies. Acta Trop. 2014;131:37-40.
19. Hagan LM, Wolpe PR, Schinazi RF. Treatment as prevention and cure towards global eradication of hepatitis C virus. Trends Microbiol. 2013;21(12):625-633.

20. Bouscaillou J, Champagnat J, Luhmann N, et al. Hepatitis C among people who inject drugs in Tbilisi, Georgia: an urgent need for prevention and treatment. Int J Drug Policy. 2014;25(5):871-878.

21. Milne GJ, Halder N, Kelso JK. The cost effectiveness of pandemic influenza interventions: a pandemic severity based analysis. PLoS One. 2013;8(4):e61504.

22. Halloran ME, Longini IM, Cowart DM, Nizam A. Community interventions and the epidemic prevention potential. Vaccine. 2002;20(27-28):3254-3262.

23. Radosavljević V, Jakovljević B. Bioterrorism - types of epidemics, new epidemiological paradigm and levels of prevention. Public Health. 2007;121(7):549-557.

24. Iacoviello D, Stasio N. Optimal control for SirC epidemic outbreak. Comput Methods Programs Biomed. 2013;110(3):333-342.

25. Centers for Disease Control and Prevention. Lesson 1: Introduction to epidemiology; 2012. Available from: https://www.cdc.gov/ophss/csels/ dsepd/ss1978/lesson1/section11.html. Accessed December 13, 2018.

26. Wikipedia. Endemic (epidemiology); 2018. Available from: https:// en.wikipedia.org/wiki/Endemic_(epidemiology). Accessed December 13, 2018.

27. Medley GF, Vassall A. When an emerging disease becomes endemic. Science. 2017;357(6347):156-158.

28. Yu FF, Ping ZG, Yao C, Wang ZW, Wang FQ, Guo X. Evaluation of the sensitivity and specificity of the new clinical diagnostic and classification criteria for Kashin-Beck disease, an endemic osteoarthritis, in China. Biomed Environ Sci. 2017;30(2):150-155.

29. National Health and Family Planning Commission of the People's Republic of China. Chinese Health Statistical Year Book, 2017. Beijing: Peking Union Medical College Press; 2018.

30. Chinese Center for Disease Control and Prevention. National Guidelines for the Work of Key Endemic Diseases Annual Report (Trial). In: Endemic Disease Control Center, ed. 2011. Available from: https:// www.docin.com/p-913540998.html. Accessed February 22, 2019.

31. National Health Commission of the People's Republic of China. Notice of the National Health Commission of the People's Republic of China on the Evaluation Measures of the Key Endemic Disease Control and Elimination. In: National Health \& Family Planning Commission of People's Republic of China (NHFPC), ed. 2014. Available from: http:// www.nhfpc.gov.cn/jkj/s5873/201412/04743057d8574190b1b91818bc 55ea43.shtml. Accessed February 22, 2019.

32. National Health Commission of the People's Republic of China. The "13th Five-Year" National Endemic Disease Prevention and Control Plan. In: National Health \& Family Planning Commission of People's Republic of China (NHFPC), ed. 2017. Avalable from: http://www.nhc. gov.cn/jkj/s5873/201703/67e87178addf4957b13d83f55583927d.shtml. Accessed March 02, 2019.

33. Atun RA, Lebcir RM, Drobniewski F, McKee M, Coker RJ. High coverage with HAART is required to substantially reduce the number of deaths from tuberculosis: system dynamics simulation. Int J STD AIDS. 2007;18(4):267-273.

34. Hassmiller Lich K, Osgood ND, Mahamoud A. Using system dynamics tools to gain insight into intervention options related to the interaction between tobacco and tuberculosis. Global Health Promotion. 2010;17(Suppl 1):7-20.

35. Huang SK, Lin MT, Chen HC, Huang SC, Wu MH. Epidemiology of Kawasaki disease: prevalence from national database and future trends projection by system dynamics modeling. J Pediatr. 2013;163(1): 126-131.

36. Frerichs LM, Araz OM, Huang TT-K. Modeling social transmission dynamics of unhealthy behaviors for evaluating prevention and treatment interventions on childhood obesity (Vol 8, e82887, 2013). PLoS One. 2014;9(5).

37. Sabounchi NS, Hovmand PS, Osgood ND, Dyck RF, Jungheim ES. A novel system dynamics model of female obesity and fertility. Am J Public Health. 2014;104(7):1240-1246. 
38. Fallah-Fini S, Rahmandad H, Huang TT, Bures RM, Glass TA. Modeling us adult obesity trends: a system dynamics model for estimating energy imbalance gap. Am J Public Health. 2014;104(7):1230-1239.

39. Wakeland W, Nielsen A, Schmidt TD, et al. Modeling the impact of simulated educational interventions on the use and abuse of pharmaceutical opioids in the United States: a report on initial efforts. Health Educ Behav. 2013;40(1 Suppl):74S-86S.

40. Weeks MR, Li J, Liao S, et al. Multilevel dynamic systems affecting introduction of HIV/STI prevention innovations among Chinese women in sex work establishments. Health Educ Behav. 2013;40(Suppl 1): $111 \mathrm{~S}-122 \mathrm{~S}$.

41. Atun RA, Lebcir RM, McKee M, Habicht J, Coker RJ. Impact of joinedup HIV harm reduction and multidrug resistant tuberculosis control programmes in Estonia: system dynamics simulation model. Health Policy. 2007;81(2-3):207-217.

42. Viana J, Brailsford SC, Harindra V, Harper PR. Combining discrete-event simulation and system dynamics in a healthcare setting: a composite model for chlamydia infection. Eur J Oper Res. 2014;237(1):196-206.

43. Hutber AM, Kitching RP, Fishwick JC, Bires J. Foot-and-mouth disease: the question of implementing vaccinal control during an epidemic. Vet J. 2011;188(1):18-23.

44. Johnston WT, Vial F, Gettinby G, et al. Herd-level risk factors of bovine tuberculosis in England and Wales after the 2001 foot-and-mouth disease epidemic. Int J Infect Dis. 2011;15(12):e833-e840.

45. National Health and Family Planning Commission of the People's Republic of China. Chinese Health Statistical Year Book, 2015. Beijing: Peking Union Medical College Press; 2016.
46. Yu W, Li M, Ge Y, et al. Transformation of potential medical demand in China: a system dynamics simulation model. J Biomed Inform. 2015;57:399-414.

47. Zardo P, Collie A, Livingstone C. External factors affecting decisionmaking and use of evidence in an Australian public health policy environment. Soc Sci Med. 2014;108:120-127.

48. Agyepong IA, Nagai RA. "We charge them; otherwise we cannot run the hospital" front line workers, clients and health financing policy implementation gaps in Ghana. Health Policy. 2011;99(3):226-233.

49. Gilson L, Mills A. Health sector reforms in sub-Saharan Africa: lessons of the last 10 years. Health Policy. 1995;32(1-3):215-243.

50. Liu X, Mills A. Financing reforms of public health services in China: lessons for other nations. Soc Sci Med. 2002;54(11):1691-1698.

51. Neil JB, Katherine C, Jeremiah H, Logan M, Stuart M, David C. An experimental investigation of mixed systems of public and private health care finance. J Econ Behav Organ. 2012;84:713-729.

52. Singh SR. Public health spending and population health: a systematic review. Am J Prev Med. 2014;47(5):634-640.

53. Flores G, Ir P, Men CR, O’Donnell O, van Doorslaer E. Financial protection of patients through compensation of providers: the impact of health equity funds in Cambodia. J Health Econ. 2013;32(6):1180-1193.

54. Jing L, Li Y, Zhang M, et al. The research on financial assistance performance evaluation mechanism in the urban community public health services [in Chinese]. Chinese Health Econ. 2009;28(4):42-44.

55. He X, Lei J, Chen Z, Yu J, Yu M. Analysis of funds that disease prevention and control institutions get from different channels [in Chinese] Chin J Public Health Manag. 2007;23(2):119-120.
Infection and Drug Resistance

\section{Publish your work in this journal}

Infection and Drug Resistance is an international, peer-reviewed openaccess journal that focuses on the optimal treatment of infection (bacterial, fungal and viral) and the development and institution of preventive strategies to minimize the development and spread of resistance. The journal is specifically concerned with the epidemiology of antibiotic

\section{Dovepress}

resistance and the mechanisms of resistance development and diffusion in both hospitals and the community. The manuscript management system is completely online and includes a very quick and fair peerreview system, which is all easy to use. Visit http://www.dovepress.com/ testimonials.php to read real quotes from published authors. 